\title{
Trachoma in Yunnan province of southwestern China: findings from trachoma rapid assessment
}

\author{
Min $\mathrm{Wu}^{1,2^{*} \dagger}$, Zhu Lin $\mathrm{Hu}^{1,2^{*}+}$, Dan $\mathrm{He}^{1,2}$, Wen Rong $\mathrm{Xu}^{1,2}$ and Yan $\mathrm{Li}^{1,2}$
}

\begin{abstract}
Background: To understand the situation of active trachoma among children aged 6 to 8 years old and scarring trachoma among those aged 15 and over in Yunnan Province, South-western China.

Methods: A rapid assessment of trachoma was conducted to determine the presence or absence of trachoma in Yunnan. Through risk assessment, 9 sites in 8 suspected trachoma epidemic counties were selected. Trachoma Rapid Assessment was conducted in these areas afterwards. Within each sites, 50 students from grade one in local primary school and adults aged 15 and above with suspected scarring trachoma were examined by survey teams.

Results: A total of 450 children aged 6-8 years and 160 adults aged 15 and above were screened in 9 sites of 8 counties. Only 1 case of active trachoma was found. Detection rate of active trachoma in children was 0.2\%(1/450) in all sites and 2\% (1/50)in Pingbian County. Out of 150 adults only 1 case of $\Pi$ and 1 case of CO were found in all the highest at risk communities. People with scarring trachoma were aged over 60 years.

Conclusions: The active trachoma was rarely seen and trachoma is unlikely to be a significant public health problem in Yunnan Province, South-western China.
\end{abstract}

Keywords: Trachoma, Rate, Trachomatous folliculs, Trachomatous trichiasis, Corneal opacity

\section{Background}

It is well known that trachoma is an infectious chronic infectious ocular surface disorder caused by the bacterium Chlamydia trachomatis, and one of the main blinding diseases, especially in Africa. An estimated 2.2 million persons are visually impaired due to trachoma, among which 1.2 million are blind [1,2]. Conjuctival inflammation is the main characteristic in primary infection of trachoma. As a result of repeated infection, trichiasis and corneal scar may present at late stage which can cause irreversible visual loss [3]. Trachoma is more common in communities with underdeveloped economy, drought and poor sanitation $[4,5]$. Data from the Ministry of Health in China showed that the prevalence

\footnotetext{
* Correspondence: ynwumin@126.com; hzl77@263.net

tEqual contributors

${ }^{1}$ Department of Ophthalmology, Yunnan Key Laboratory for prevention and treatment of eye diseases, Yunnan Innovation Team for Cataract and Ocular fundus Disease (2017HC010), Yunnan Eye Institute, Yunnan Eye Hospital, The 2nd People's Hospital of Yunnan Province, Kunming, China

Full list of author information is available at the end of the article
}

of trachoma ranged from 63.0\% 98.0\% in 1958 [6]. In the first national survey of blindness and low vision in China, trachoma was the second cause of visual impairment $[7,8]$. Trachoma interventions were implemented in China for decades. Following the WHO recommendations to reach the target of WHA51.11 Global elimination of blinding trachoma [9], a trachoma rapid assessment (TRA) was carried out in 14 provinces in $\mathrm{P}$. R.China as a key activity to determine the current situation of trachoma and provide information for future planning. Yunnan province locates in the southwest border of China and is at the far eastern edge of the Himalayan uplift. Yunnan has an area of 394,100 km², 4 . $1 \%$ of the nation's total, and shares a border of $4060 \mathrm{~km}$ with Myanmar, Laos and Vietnam. Mountain land accounts for almost $94 \%$ of its total area. The elevation ranges from 76.4 to $6740 \mathrm{~m}$ and the average annual rainfall ranges from 584 to $2300 \mathrm{~mm}$. Because of diverse climate and poor traffic conditions, economic development level in Yunnan is relatively backward with more poverty-stricken 
counties. The prevalence of trachoma was as high as $63.1 \%$ in Yunnan Province in 1963 [10]. In 1987, trachoma was reported as one of the three leading causes of blindness in the National survey of blindness in Yunnan. Among 109,181 participants, 107 people were blind caused by trachoma (0.098\%) [8]. In 1999, the government of China included Yunnan as one of 12 provinces in which trachoma was still believed to be present [11]. In recent years, trachoma continued to be reported in school health reports [1214]. Severe drought in recent years led to a shortage of drinking water in 7.42 million people. In the majority of mountainous and the mid-altitude level districts across the province, it is common practice for the whole family to use the same basin of water for face washing. Yunnan Province has been assumed by the government as a region in which trachoma was a public health problem. However, a large scale prevalence survey has so far not been carried out in Yunnan Province and assumptions are commonly based on clinical reports only. As part of a number of TRAs conducted across the country, a TRA was also conducted in Yunnan Province. Purpose of the survey was to assess the presence of active disease, defined as trachomatous inflammation, follicular (TF) and/or trachomatous inflammation, intense (TI) among children aged from 6 to 8 and trachomatous trichiasis (TT) and/or trachoma-related corneal opacity (CO) among those aged 15 and over.

\section{Methods}

\section{Ethical considerations}

The protocol for this trachoma survey was approved by the Ethical Committee of The 2nd People's Hospital of Yunnan Province, China. During the survey, informed consent was given by every adult and the parents of all enrolled children. The study procedure was explained to the parents, teachers and students by survey staff. The guidelines of the Declaration of Helsinki were strictly followed during the survey.

\section{Study sites}

The WHO recommended standard methodology for TRA $[15,16]$ was followed in this survey, including purposive sampling of choosing villages/communities where trachoma is likely to exist. A first phase of investigation was carried out to gather evidence of trachoma, its complications and socioeconomic information in Yunnan. According to the national population census in 2010, the total population in Yunnan Province was 45.9 million. Yunnan Province was divided into 230 districts consisting of populations between 150,000 to 200,000 people. The suspected trachoma epidemic areas were determined within all districts based on the following factors: 1) geographically remote; 2) poor economic development; 3) poor access to water; 4) known highepidemic and endemic trachoma areas; 5) poor access to health care; and 6) low socio-economic status. Evidence of known endemic trachoma areas, e.g. The number of trichiasis surgical cases performed annually and number of corneal opacity cases seen in recent 5 years, was collected from two sources: literature review and key informants, such as eye doctors, ophthalmic nurses and public health workers. Based on this information, eight counties were identified as suspected trachoma epidemic areas: Daguan, Binchuan, Fuyuan, Mojiang, Shuangjiang, Pingbian, Xichou, and Yuanmou county (See Fig. 1). Nine towns with poor socio-economic status (environmental, sanitation and water supply were also considered) in eight counties were defined as survey clusters.

\section{Participants}

Target population of the survey included the children aged 6 to 8 years for active trachoma and adults aged 15 years and over for blinding trachoma (TT and $\mathrm{CO}$ ). The gross enrollment rates of primary education in China was estimated as $99.8 \%$ in 2014 [17]. Thus for children, a school-based survey was applied. With the help of the local Education Bureau, a list of primary schools in the selected towns was generated and one primary school per town was randomly selected for screening of active trachoma. One class of grade one students in the defined primary school was selected randomly. If the number of students in the class was more than 50 , the first 50 students were documented as participants in the survey. When the number of students in the class was less than 50, more students would be recruited from the neighboring class until 50 students were examined. Adult participants were recruited via pre-screening by key informants. One week before the survey team arrived, local village leaders, teachers and village/township doctors etc., were requested to identify adults aged $\geq 15$ years old with trichiasis and corneal opacity door to door. People identified were invited to the township hospital and confirmed by survey team.

\section{Trachoma grading}

Two survey teams were organized and each team included 1 ophthalmologist, 1 field assistant (local ophthalmologist) and 1 driver. One ophthalmologists in each survey team was trained by World Health Organization (WHO) experts during a workshop held by the China Ministry of Health in Beijing. The WHO simplified grading system was taught and applied to identify trachoma. The two trained ophthalmologists led the survey teams. Trachoma was categorized into five grades according to the WHO trachoma grading system [18]: trachomatous inflammation, follicular (TF), trachomatous inflammation, intense (TI), trachomatous trichiasis (TT), trachomatous scarring (TS) and corneal opacity $(\mathrm{CO})$. TF is defined as five or more off-white follicles 


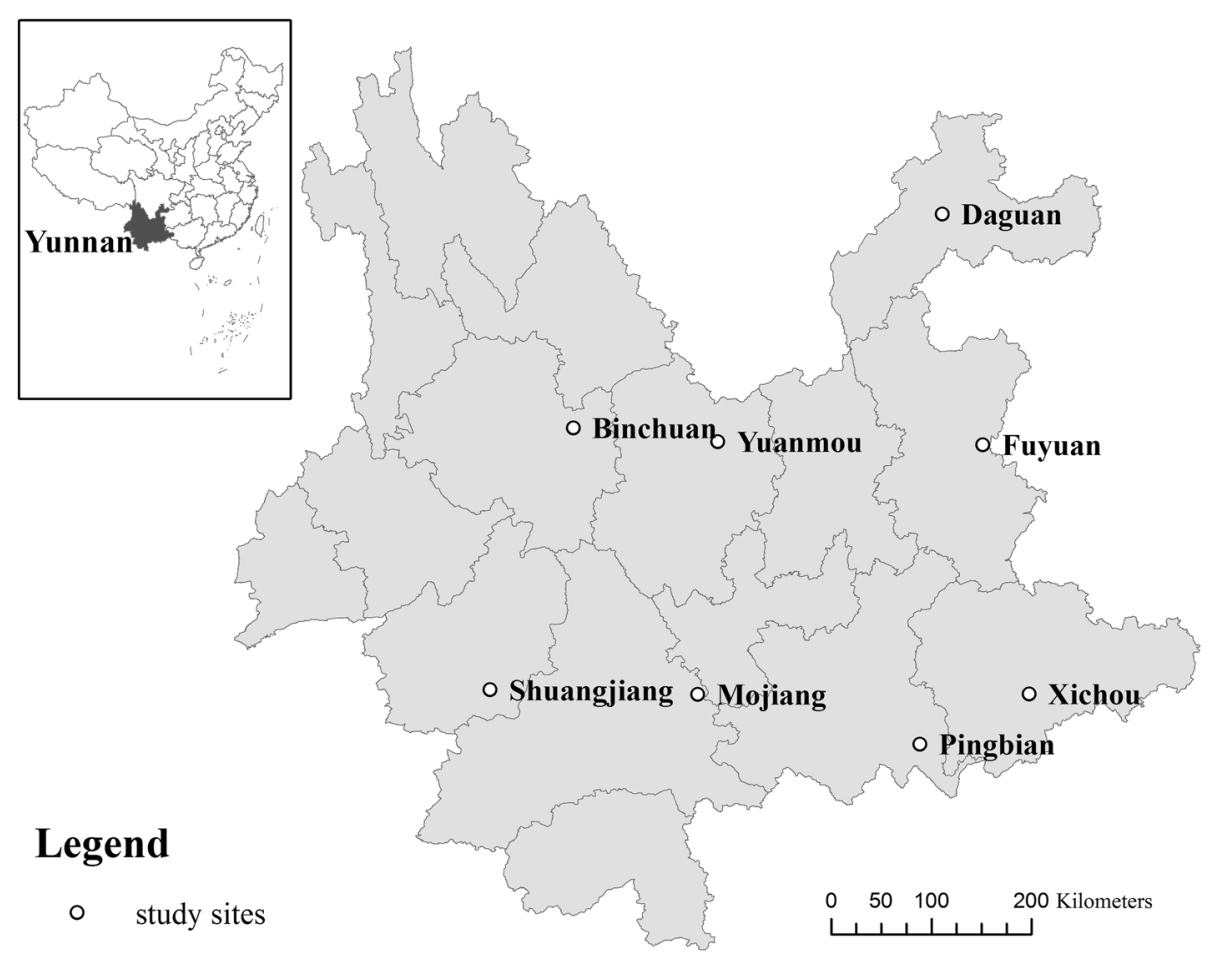

Fig. 1 Location of survey area. Up-left figure showed the location of Yunnan Province in China. The eight circles showed the survey areas of TRA in Yunnan Province

of $0.5-2.0 \mathrm{~mm}$ on the upper tarsal conjunctiva; TI is defined as inflammatory thickening of the upper tarsal conjunctival tissues obscuring more than half the deep tarsal vessels; TS is defined as small scarring in tarsal conjunctiva forming dense fibrotic tissue and distortion of normal lid architecture; TT is defined as at least one eyelash ingrown and touching the globe; $\mathrm{CO}$ is defined as corneal opacity which covers part of pupil margin as a result of ingrown eyelashes or secondary bacterial infections. "Active trachoma" was defined as TF and/or TI in either eye. "Scarring trachoma" was defined as TS, TT and/or CO in either eye. A WHO trachoma grading card and slides were carried by survey team.

\section{Examination of trachoma}

After written informed consent was obtained from parents, all the students were examined by trained ophthalmologists using a torch and a $2.5 \times$ magnifying binocular loupe. The examiner sat opposite to the student, examining for signs of inflammation ( $\mathrm{TF}$ and $\mathrm{TI}$ ) on the upper conjunctiva after turning of upper lid. Between examinations, hand disinfectant was applied to clean the examiners' hands. Once TF or TI was detected in any student, single dose of Azithromycin was prescribed. Health education information including face washing and strategies against infection was given to students, teachers and parents.
If active trachoma case was detected in non-boarding schools of any survey site, at least 50 children including the siblings of detected case would be examined in the community. If the case was detected in a boarding school, at least 50 students in the same school would be examined for trachoma.

All the adults aged 15 and above screened with suspected TT and/or CO were informed and gathered in the township hospital on the survey day. The survey team examined everyone following the same procedure used in children screening. People with TS, TT and/or $\mathrm{CO}$ were documented and people with $\mathrm{TT}$ and/or $\mathrm{CO}$ were referred to the county hospital for further treatment. Other people with treatable diseases were also referred to the county hospital.

\section{Data analysis}

Double entry of data were performed by two survey staff at the end of each survey day using Microsoft Office Excel 2010(Microsoft Corporation, USA). Integrity of data and consistency check were conducted. Statistical analysis was conducted using SPSS 16.0 software (SPSS Corporation, USA). The percentage of active and scarring trachoma was calculated. The association between risk factors and rate of trachoma was analyzed using Univariate analysis method. 


\section{Results}

\section{Detection rate of trachoma}

In total, 450 eligible children and 165 people aged 15 and above were examined in this survey. The response rate in students was $100.0 \%(450 / 450)$ and $96.97 \%$ in people aged 15 and above (160/165). The female to male ratio in children and adults examined was 0.95:1 and 1 . 96:1, respectively. All the children screened were aged from 6 to 8 years old. In adults aged $\geq 15$ years old, the age ranged 15 to 88 years, with a median age of 59 years. In children, 1 case of TF was detected in Pingbian County and oral azithromycin tablets was prescribed. No case of TI was detected. The percentage of TF was 0 . $2 \%$ (95\%CI: $0.04-1.2 \%)(1 / 450)$ in total and 2\% (95\%CI:0. $4-10.5 \%)(1 / 50)$ in Pingbian County. In people aged 15 and above, the percentage of TS, TT and CO in "trachoma suspects" was 3.1\% (95\% CI: 1.3-7.1\%)(5/160), 0.6\% (95\%CI: $0.1-3.5 \%)(1 / 160)$ and $0.6 \%$ (95\%CI: $0.1-3.5 \%)(1 /$ $160)$, respectively. The overall detection rate of active trachoma and scarring trachoma was $0.2 \%$ and $4.4 \%$, respectively. The detection rate of active and scarring trachoma by survey sites is shown in Table 1 . No trachoma was detected in all the remaining survey sites. People detected with TS, TT or CO were aged from 63 to 80 years with median age of 70 years. Within scarring trachoma cases, the $\mathrm{CO}$ case was male $(14.3 \%)$ and other cases of TT or TS were female $(85.7 \%)$. Although the detection rate of scarring trachoma in females was higher than that in males, there was no statistically significant association between sex and scarring trachoma $(p=0.85)$.

\section{Further investigation of school where TF case was detected}

Since one student with TF was found in Pingbian county, the details of the student were investigated. This student was a 7 year old boy and studied in grade one of a boarding school. The dormitory, water supply and environment were inspected in the school. The school had sufficient clean water supply and children could wash face using clean water every day and take shower once a week. The dormitory accommodated 15 students from different classes of grade one or two. 76 students in grade one and in the same or neighboring dormitory were examined by the survey team. One student with TF was detected in this group and oral azithromycin tablets was prescribed. This student was the first detected TF child's roommate and shared the same towel. Health education on "F" strategy was given to the children, teachers and parents.

\section{Discussion}

The WHO led Global Alliance for the Elimination of Trachoma (GET2020) aims to elimination the disease as a public health problem in the world by 2020 . The key trachoma control strategy is SAFE strategy endorsed by WHO: "surgery" for patients with advanced disease, "antibiotics" azithromycin or tetracycline eye ointment for active trachoma, "facial" cleanliness and "environmental" improvement on water supply and sanitation $[4,5]$. In spite of implementation of SAFE strategy, data from Ethiopia [19], Sudan [20], India [21, 22] and countries in Pacific island [23] indicated trachoma is epidemic. The rate of active trachoma ranged from $25.2 \%-71.0 \%$ [1923]. Trachoma was endemic and the second cause of blindness in China, also in Yunnan Province [6-8, 10]. School health reports showed that the detection rate of active trachoma in primary and middle school students was $29.56 \%$ and $18.24 \%$ in Fuyuan County in year 2000 [10], and 5.21\% in BinChuan County in 2004 [12]. To reduce the trachoma, Ministry of Health in China had launched trachoma intervention programs nationwide since 1960s'. With the intervention of SAFE strategy, findings from several population-based epidemiological studies revealed that trachoma was no longer main cause of blindness in China, including Yunnan Province [2429]. In our TRA in Yunnan Province, only one case of TF was detected out of 450 6-8 years children and the detection rate of active trachoma was only $0.2 \%$ in all the nine survey sites. Hence we conclude that active trachoma is sporadic in Yunnan Province nowadays. The finding is comparable with the findings of very low detection rate of active trachoma from TRA studies in the neighboring Sichuan province, Hainan province and Shandong province [30-32]. The improvement of school environment and general hygiene in community likely contributed to a decrease of trachoma. In the past, almost every village had one primary school. However, most of the schools had very poor infrastructure and

Table 1 Detection rate of trachoma in all the survey sites

\begin{tabular}{|c|c|c|c|c|c|c|c|c|}
\hline \multirow[t]{2}{*}{ County } & \multirow{2}{*}{$\begin{array}{l}\text { Survey } \\
\text { site }\end{array}$} & \multirow{2}{*}{$\begin{array}{l}\text { No. of children } \\
\text { examined }\end{array}$} & \multirow{2}{*}{$\begin{array}{l}\text { No. of adults } \geq 15 \\
\text { years old examined }\end{array}$} & \multicolumn{2}{|c|}{ Active trachoma(\%) } & \multicolumn{3}{|c|}{ Scarring trachoma(\%) } \\
\hline & & & & $\mathrm{TI}(\%)$ & $\mathrm{TF}(\%)$ & $\mathrm{TS}(\%)$ & $\pi(\%)$ & $\mathrm{CO}(\%)$ \\
\hline Fuyuan & Dahe & 50 & 29 & $0(0.0 \%)$ & $0(0.0 \%)$ & $3(10.3 \%)$ & $0(0.0 \%)$ & $0(0.0 \%)$ \\
\hline Pingbian & Baihe & 50 & 21 & $0(0.0 \%)$ & $1(2.0 \%)$ & $0(0.0 \%)$ & $0(0.0 \%)$ & $0(0.0 \%)$ \\
\hline Shuangjiang & Bangbing & 50 & 23 & $0(0.0 \%)$ & $0(0.0 \%)$ & $2(8.7 \%)$ & $1(4.3 \%)$ & $1(4.3 \%)$ \\
\hline Other 4 counties & 4 sites & 300 & 87 & $0(0.0 \%)$ & $0(0.0 \%)$ & $0(0.0 \%)$ & $0(0.0 \%)$ & $0(0.0 \%)$ \\
\hline Total & & 450 & 160 & $0(0.0 \%)$ & $1(0.2 \%)$ & $5(3.1 \%)$ & $1(0.6 \%)$ & $1(0.6 \%)$ \\
\hline
\end{tabular}


insufficient water supply. During the past 10 years, merging of primary schooling had been completed. Small schools in villages were merged into one central school in town. As a result of increased governmental input to the central schools, the school environment, including water supply, was improved.

Out of 450 children and 150 adults only 1 case of TF, 1 case of TT and 1 case of $\mathrm{CO}$ were found in the highest at risk communities. Our study proposes that trachoma is unlikely to be a significant public health problem in Yunnan Province. The presence of blinding trachoma in elderly people aged over 60 years could be a sequelae of high epidemic active trachoma in several decades ago. Screening of scarring trachoma suspect people recommended by key informants would be a realistic solution to find people with TT and/or CO who need surgical services. People aged $\geq 60$ years should be the target population for finding scarring trachoma suspect.

TRA is a cost-effective fast survey method recommended by WHO and validated in many countries worldwide. The applications of TRA comprised determining the presence or absence of endemic trachoma, whether or not trachoma is a blinding disease, or prioritizing communities with trachoma for treatment [33]. The TRA was completed in the mountainous region within one month by six survey staffs. It covered 9 sites in 8 counties, which spread in the different directions of Yunnan Province. The longest travel distance was $800 \mathrm{~km}$ from the capital city to the survey site. It shows that TRA is an useful tool which can provide an overview of presence or absence of trachoma, even in a mountainous region.

There are some limitations in this study: (1) During screening of scarring trachoma, survey teams did not look for cases using door to door method, but only examined suspected people in township hospitals. There might be selection bias in this process. Some adults with scarring trachoma could be missed when key informants screened in community. For the children, we did schoolbased survey only. Considering the enrollment rate of primary school in Yunnan Province was 99.5\% in 2013, the school children are likely to be good representatives. (2) Microbiological investigation was not conducted in the detected TF case. However the clinical signs in the only TF case fulfilled WHO grading system.

\section{Conclusion}

Active trachoma is a rare condition and scarring trachoma is mainly found in people aged over 60 years old. Trachoma is unlikely to be a significant public health problem in Yunnan Province. Large scale of population-based survey and trachoma prevention program are not necessary. Efforts should be input to find possible blinding trachoma (TT and/or CO) in limited regions and surgical services for trichiasis should be provided when necessary.

\section{Abbreviations}

ASTRA: Acceptance sampling trachoma rapid assessment; CO: Trachomarelated corneal opacity; CRS: cluster random sampling; ENT: Ear, nose \& throat; SAFE: Surgery for people at immediate risk of blindness; Antibiotic therapy to treat individual active cases and reduce the community reservoir of infection; Facial cleanliness and improved hygiene to reduce transmission; Environmental improvements to make living conditions better so that the environment no longer facilitates the maintenance and transmission of trachoma; TF: Trachomatous follicular; TI: Trachomatous inflammation intense; TRA: Trachoma rapid assessment; TT: Trachomatous trichiasis; WHO: World Health Organization

\section{Acknowledgments \\ Sincerely acknowledgments should be given to the Health \& Family Planning Committee of Yunnan Province, health workers and school staff in all the eight survey sites for the strong support in this survey. We also would like to thank Hai Liu, Jia Gao,Yuan Fang, Chun Li Li and all the investigators in this survey for their devotion. Deeply acknowledgement should be given to Professor Andreas Mueller for revising the paper.}

Funding

This study is supported by Sight First China Action Project(SFCA-26-2013-01).

\section{Availability of data and materials}

The datasetsdata sets of this study are available from the corresponding author upon reasonable request.

\section{Authors' contributions}

WM carried out the study design, acquisition of data, analysis and interpretation of data and drafted the manuscript. HZL contributed to the study design, revising and give the final approval of the version. HD participated in the design of the study. XWR and LY participated in the data acquisition. All authors read and approved the final manuscript.

\section{Ethics approval and consent to participate}

This study adheres to the tenets of the Declaration of Helsinki and was approved by the the Ethical Committee of The 2nd People's Hospital of Yunnan Province, China. During the survey, informed consent was given by every adult and the parents of all enrolled children.

\section{Competing interests}

The authors declare that they have no competing interests.

\section{Publisher's Note}

Springer Nature remains neutral with regard to jurisdictional claims in published maps and institutional affiliations.

\section{Author details}

${ }^{1}$ Department of Ophthalmology, Yunnan Key Laboratory for prevention and treatment of eye diseases, Yunnan Innovation Team for Cataract and Ocular fundus Disease (2017HC010), Yunnan Eye Institute, Yunnan Eye Hospital, The 2nd People's Hospital of Yunnan Province, Kunming, China. ${ }^{2}$ Department of Ophthalmology, The 4th Affiliated Hospital of Kunming Medical University, Kunming, Yunnan, China.

Received: 28 February 2017 Accepted: 3 April 2018

Published online: 17 April 2018

References

1. World Health Organization. Global data on visual impairment 2010. http:// www.who.int/blindness/GLOBALDATAFINALforweb.pdf?ua=1) Accessed 24 June 2015.

2. World Health Organization. Global alliance for the elimination of blindng trachoma by 2020. Wkly Epidemiol Rec. 2013;88(24):241-56.

3. Hu VH, Harding-Esch EM, Burton MJ, Bailey RL, Kadimpeul J, et al. Epidemiology and control of trachoma: systematic review. Tropical Med Int Health. 2010;15:673-91.

4. Stocks ME, Ogden S, Haddad D, Addiss DG, McGuire C, Freeman MC. Effect of water, sanitation, and hygiene on the prevention of trachoma: a systematic review and meta-analysis. PLoS Med. 2014;11(2):e1001605. 
5. Dye C, Mertens T, Hirnschall G, Mpanju-Shumbusho W, Newman RD, Raviglione MC, Savioli L, Nakatani H. WHO and the future of disease control programmes. Lancet. 2013;381:413-8.

6. Medical Prevention Buearu, Ministry of Health of China. Data compilation of National Trachoma prevention on-site meeting. Beijing: People's Health Publisher; 1959. p. 40-59.

7. Zhang SY, Zou LH, Gao YQ, Di Y, Wang XD. National epidemiological survey of blindness and low vision in China. Chin Med J(Engl)[J]. 1992;105(7):603-8.

8. Shang CX, Zhang XM, Pan X. The epidemiological study of blindness and low vision in Yunnan Province. Chin J. Ophthalmology. 1988;24:331-3.

9. WHA 51.11 Global elimination of blinding trachoma, 16 May 1998. (http://www/ who.int/blindness/causes/WHA 51.11/en/index.html, Accessed Sept 2015.).

10. Sanitation and antiepidemic station of Wenshan Region in Yunnan Province. The survey of trachoma in rural area of Wenshan Zhuang and Miao autonomous region in Yunnan Province. Chin J Ophthalmology. 1965;12(4):303-4.

11. WHO Programme for the Prevention of Blindness and Deafness. First national workshop on the assessment and management of trachoma in the People's Republic of China: Kunming, Yunnan Province, People's Republic of China, 1-4 November 1999 : conclusions and recommendations. Geneva; World Health Organization; 2000. p. 28.

12. Gao GS. The survey of common diseases in students in Fuyuan County. Chin J School Health. 2000;21(6):472.

13. Zhang JJ, Pu GM, Fu X. The epidemiological survey of blindness and low vision in Pingbian Miao minority Autonomous County, Yunnan Province. Med J Chin People's Armed Police Forces. 2002;13(10):598-601.

14. He X, Yang RT, Wu HF, Yang JX. Status of common diseases in primary and middle school students in Binchuan County. Chin J School Health. 2005; 26(9):763-4.

15. Negrel AD, Mariotti SP. Trachoma rapid assessment: rationale and basic principles. Community Eye Health. 1999;12(32):51-3.

16. World Health Organization. London School of Hygiene of tropical medicine, International Trachoma Initiative. Trachoma control-a guide for programme managers. Geneva: World Health Organization, London School of Hygiene of tropical medicine, International Trachoma Initiative; 2006.

17. Yuan LS, He TT, Li ZY. Estimating the 2000-2014 gross enrollment rates of primary and secondary education in China. China Econ Educ Rev. 2017;3:3-19.

18. Baneke A. Review: targeting trachoma: strategies to reduce the leading infectious cause of blindness. Travel Med Infect Dis. 2012;10(2):92-6. Br J Ophthalmol, 2012, 10(2):92-96

19. Ejigu M, Kariuki MK, llako DR, Gelaw Y. Rapid trachoma assessment in Kersa District, Southwest Ethiopia. Ethiop J Health Sci. 2013;23(1):1-9.

20. Edwards T, Smith J, Sturrock HJW, Kur LW, Sabasio A, Finn TP, Lado M, Haddad D, Kolaczinshi JH. Results from a large-scale population-based survey and potential implications for further surveys. PLoS Negl Trop Dis. 2012;6(4):e1585

21. Khanduja S, Jhanji V, Sharma N, Vshist P, Murthy GVS, Gupta SK, et al. Trachoma prevalence in women living in rural northern India: rapid assessment findings. Ophthalmic Epidemiol. 2012;19(4):216-20.

22. Vashist P, Gupta N, Rathore AS, Shah A, Singh S. Rapid assessment of trachoma in underserved population of car-nicobar island, India. PLoS One. 2013;8(6):e65918.

23. Mathew AA, Keeffe JE, Mesurier RTL, Taylor HR. Trachoma in the Pacific Islands: envidence from trachoma rapid assessment. Br J Ophthalmo. 2009; 93:866-70.

24. Tang Y, Wang Y, Wang J, Huang W, Gao Y, Luo Y, Lu Y. Prevalence and causes of visual impairment in a Chinese adult population: the Taizhou eye study. Ophthalmogy. 2015;122(7):1480-8.

25. Yao Y, Shao J, Sun W, Zhu J, Hong FD, Guan H, Liu Q. Prevalence of blindness and causes of visual impairment among adults aged 50 years or above in southern. Jiangsu Province of China. Pak J Med Sci. 2013;29(5):1203-7.

26. Wu M, Yip J, Kuper H. Rapid assessment of avoidable blindness in Kunming. China Opthalmol. 2008;115(6):965-74.

27. Cai N, Yuan YS, Zhao JL, Zhong H, Ellwein LB, Chen MM, et al. Prevalence and causes of blindness and moderate and severe visual impairment among adults aged 50 years or above in Luxi County of Yunnan Province: the China Nine-Province survey. Zhonghua Yan Ke Za Zhi. 2013;49(8):901-6.

28. Cheng JW, Cheng SW, Cai JP, Li Y, Wei RL. The prevalence of visual impairment in older adults in mainland China: a systematic review and meta-analysis. Ophthalmic Res. 2013:49(1):1-10.
29. Li X, Zhou Q, Sun L, Wang Z, Han S, Wu S, Wang N. Prevalence of blindness and low vision in a rural population in northern China: preliminary results from a population-based survey. Ophthalmic Epidemiol. 2012;19(5):272-7.

30. Chen H, Wu X, Wei M, Eichner JE, Fan Y, Zhang Z, Lei C, Stone DU, Yang J. Changes in the prevalence of visual impairment due to blinding trachoma in Sichuan Province, China: a comparative study between 1987 and 2006. Ophthalmic Epidemiol. 2012;19(1):29-37.

31. Liu H, Ou B, Paxton A, et al. Rapid assessment of trachoma in Hainan Province, China: validation of the new World Health Organization methodology. Ophthalmic Epidemiol. 2002;9:97-104.

32. Qu Y, Bi H, Wen Y, Li C, Wu H. Trachoma rapid assessment in Shandong province of China. Chin Med J(Engl). 2014;127(14):2668-71.

33. Ngondi J, Reacher M, Matthews F, Brayne C, Emerson P. Trachoma survey methods: a literature review. Bull World Health Organ. 2009;87(2):143-51.

\section{Ready to submit your research? Choose BMC and benefit from:}

- fast, convenient online submission

- thorough peer review by experienced researchers in your field

- rapid publication on acceptance

- support for research data, including large and complex data types

- gold Open Access which fosters wider collaboration and increased citations

- maximum visibility for your research: over $100 \mathrm{M}$ website views per year

At BMC, research is always in progress.

Learn more biomedcentral.com/submissions 